\title{
REDES HOTELEIRAS: OS ELEMENTOS REPETITIVOS E SINGULARES NA FORMAÇÃO DE UMA LINGUAGEM
}

HOTEL CHAINS: THE UNIQUE AND SINGULAR ELEMENTS IN THE FORMATION OF A LANGUAGE

\section{VALENTE, CLAUDIO ALEXANDRE}

Mestre, Universidade Presbiteriana Mackenzie, valenteclaudioalexandre@gmail.com

\section{PERRONE, RAFAEL ANTONIO CUNHA}

Livre-docente, Universidade Presbiteriana Mackenzie, racperrone@gmail.com

\section{RESUMO}

As bases para a formação das primeiras redes hoteleiras estão atreladas ao conceito de padronização surgido com a industrialização no século XIX e às modificações sociais e econômicas do período posterior à Segunda Guerra Mundial, quando as redes se consolidam e passam a se disseminar geograficamente. Posteriormente, na década de 1970, as redes hoteleiras se internacionalizam. Paralelamente, uma segunda modernidade está se desenhando, o que acarreta no surgimento de novas categorias de hotéis, centradas em oferecer a possibilidade de experiências únicas e hedonistas a seus hóspedes. 0 presente artigo tem por objetivo identificar possíveis caminhos pelos quais as redes hoteleiras estabelecem linguagens reconheciveis por seus potenciais usuários e que sejam aplicáveis em suas expansões. Para tanto, faz-se uso de métodos de observação, por meio de visitas presenciais a empreendimentos alinhados com o objeto de estudo e análise de literatura pertinente ao tema.

PALAVRAS-CHAVE: rede hoteleira; padronização; linguagem; disseminação; singular e repetitivo.

\section{ABSTRACT}

The first hotel chains were construed based on the standardization, associated with the 19th century industrialization, and the post 2nd war social-economic movements. By that time, consolidation takes place in this market and those chains expand geographically. Subsequently, in the 70's, the hotel chains become international. In parallel, another modern concept is developing, which will allow a new hotel category to emerge, focused on unique and hedonistic experiences to their guests. This article aims to identify possible ways in which hotel chains could establish languages that are, at the same time, recognizable by their potential users and applicable in their expansions. In order to do so, this study relies on observation methods, through -site visits to projects aligned with the object of this work and pertinent literature analysis.

KEYWORDS: hotel chain; standardization; language; dissemination; unique and repetitive. 


\section{INTRODUÇÃO}

Este artigo pretende contribuir com pesquisas na área de projetos arquitetônicos e percepção de ambiente a partir do estudo sobre redes hoteleiras. Toma-se como foco, nesse estudo, a construção e disseminação de linguagens reconhecíveis por usuários potenciais dessas redes.

A pesquisa apresentada é fruto dos trabalhos desenvolvidos ao longo da carreira dos autores, tanto no âmbito acadêmico como profissional. Tratam-se de trajetórias vinculada à área de projetos arquitetônicos, no que tange a questões de linguagem, necessidades operacionais e viabilidade financeira. Dentro desse âmbito, são apresentados neste artigo alguns aspectos da pesquisa realizada pelos autores entre 2015 e 2017, dentro do programa de estudos pós-graduação da Universidade Presbiteriana Mackenzie1.

Como objeto de estudo da pesquisa, foram eleitos os saguões de entrada e os apartamentos de hotéis urbanos, enquadrados nos padrões intermediário e superior, administrados por redes hoteleiras de atuação internacional. A escolha do saguão de entrada como objeto de estudo se deve ao fato de que esse ambiente é um dos primeiros e um dos últimos contatos entre o hotel e seus hóspedes. Em geral, esse ambiente sinaliza e sintetiza a linguagem pretendida pelo hotel. Já os apartamentos são os ambientes de maior permanência dos hóspedes, permitindo maior imersão com a experiência da linguagem proposta pela rede. A pesquisa que deu origem a este artigo abrange hotéis de variadas marcas, porém adota-se aqui como estudos de caso os hotéis Grand Hyatt São Paulo e Grand Hyatt New York, pertencentes à rede hoteleira Hyatt Hotels.

O objetivo geral da pesquisa foi compreender as estratégias pelas quais as redes hoteleiras geram uma linguagem reconhecível para seu público, por meio do design. Assinala-se a natureza qualitativa da investigação, que se apropria de técnicas de observação e registro por meio de visitas presenciais a hotéis de rede alinhados aos propósitos do trabalho. Para tanto, foram empregados recursos fotográficos, anotações de impressões e de diálogos com funcionários presentes nessas visitas, visualização e percepção de materiais de acabamento e equipamentos hoteleiros. Realizaram-se entrevistas com profissionais ligados a área de projetos e operação hoteleira que apresentaram diferentes visões e estratégias das redes hoteleiras e dos agentes atuantes na construção de uma linguagem. Inventariou-se, por meio de ferramentas eletrônicas e publicações, material iconográfico para identificar, comparar e selecionar características dos hotéis inerentes ao estudo. O levantamento e a análise de literatura sobre 0 tema elucidaram questões decorrentes das observações e entrevistas realizadas, possibilitando também o entrelaçamento de conceitos que foram determinantes para o arcabouço teórico do estudo.

Vale ressaltar que nas ultimas décadas a demanda por profissionais especializados em projetos de arquitetura hoteleira cresceu substancialmente. Os hotéis em operação realizam renovações periódicas, sejam pelos desgastes naturais do uso, demandas de mercado ou ainda por atualizações de linguagem. Apesar da consolidação da indústria hoteleira, ainda há um número reduzido de profissionais, especializados na área de arquitetura e design, voltados para esse setor. Dentro deste âmbito, reafirma-se o intuito desta pesquisa em colaborar com os trabalhos realizados na área hoteleira tanto no campo acadêmico, como na práxis dos profissionais interessados no tema.

\section{CONTEXTUALIZAÇÃO}

Os pesquisadores determinaram como recorte temporal o período entre 1984 e a atualidade. Esta opção deve-se ao fato de que no referido ano ocorre a inauguração do hotel Morgans em Nova lorque, um dos pioneiros dos chamados hotéis Design. O recorte adotado na pesquisa apoiou-se, sobretudo, na hipótese de que o surgimento dessa categoria de hotel torna-se novo paradigma na indústria hoteleira. Mais do que isto, o Morgans, assim como outros hotéis design, é pioneiro no modo de pensar e estruturar novas linguagens, capazes de suscitar experiências diferenciadas e personalizadas, a partir da utilização do design, extrapolando a ideia de produto hoteleiro restrito à funcionalidade dos serviços de hospedagem tradicional.

O recorte geográfico concentra-se nas cidades de São Paulo, Nova lorque. Tais cidades possuem hotéis relevantes de redes hoteleiras como a Hyatt, o que permitiu analisar a capacidade dessa cadeia ${ }^{2}$ em disseminar geograficamente sua linguagem de forma a se tornar reconhecível por seus usuários em distintas localizações.

\section{Surgimento e desenvolvimento das redes hoteleiras}

A relação entre redes hoteleiras e padronização encontra respaldo em algumas balizas que levaram à reestruturação do modo de hospedar como as noções que privacidade que começam a se concretizar no século XVIII, assim como no fomento dos negócios e o processo de industrialização. 
Mudanças na forma de habitar que acontecem neste período geram alterações na forma hospedar. Anteriormente os ambientes não possuíam função especifica e se tramitava entre os mesmos indistintamente (Hall, 2005). As crescentes noções de privacidade resultam na habitação burguesa, em que cada cômodo e mesmo a mobília passam a apresentar funções especificas. A circulação apresenta corredores e há diferentes níveis de permeabilidade para cada ambiente. A fachada marca o limite entre a rua e o ambiente privado (BAUDRILLARD, 2009).

Analogamente, a hotelaria começa a desenhar seu formato atual. Se a hospedagem fora exercida na Idade Média por meio de quartos coletivos, nos mosteiros e posteriormente pelo Estado com o fortalecimento das monarquias europeias, no século XVIII a hotelaria começa a ser vista como negócio lucrativo. Novos meios de transporte, somados a uma crescente industrialização fomentam os deslocamentos e o comércio e, consequentemente a demanda por hospedagem. Em decorrência desse quadro, surgem iniciativas como 0 hotel Tremont House. Inaugurado em 1826 na cidade de Boston, o hotel conta com apartamentos privativos, dotados de portas com chaves e não mais do que uma ou duas camas, atributos inéditos até então. A partir desta mesma perspectiva, em 1870, César Ritz, introduz o conceito de banheiros privativos nos apartamentos do hotel onde trabalhava (PENNER, 2013; ANDRADE et al., 2014).

O modelo econômico vigente nessa época tem como força motriz a industrialização. A criação e produção, anteriormente exercidas conjuntamente pela figura do artesão, passam a ser desvinculadas. Os produtos são concebidos para serem reproduzidos em larga escala dentro de determinados padrões. Ritz vai se apropriar da padronização em voga neste período para criar diferenciações pela qual identifica tanto seu primeiro hotel como os demais que vem a inaugurar. O hoteleiro é o primeiro a introduzir o uso de uniformes por funcionários. A finalização dos pratos dos restaurantes de seus hotéis é decorada e padronizada. Ele cria processos operacionais e utiliza arranjos específicos de arquitetura de interiores também padronizados (ANDRADE et al., 2014; MILENKOVSKA, 2011; PENNER, 2013).

Ritz inaugura o conceito de cadeia hoteleira por meio da Ritz Development Company Ltd, com sede em Londres. Porém sua real contribuição não está em ter aberto a primeira rede hoteleira. Reside no fato de ter criado padrões que permitem ao público reconhecer seus hotéis em Paris, Londres e Madri como pertencentes a esta cadeia.

Nas primeiras décadas do século XX, surgem diversas redes hoteleiras. Em 1907, Ellsworth Milton Statler inicia a operação do Statler Hotel em Buffalo, Nova lorque, o maior hotel com banheiros nos apartamentos até então. Em 1913, iniciam-se as operações da Bowan-Biltmore, detentora de hotéis como o Commodore e do The Ansonia, ambos em Nova lorque (MELACHOS, 2014). Em 1919, Conrad Hilton compra, seu primeiro hotel, dando início à rede Hilton. Esta cadeia se caracteriza pelos diversos padrões implementados por seu fundador. A Hong Kong and Shanghai Hotels, inicia suas operações em 1928 na cidade de Hong Kong, e a Oberoi é inaugurada em 1934, na India (MILENKOVSKA, 2011).

Ao fim da Segunda Guerra Mundial surge um cenário de expansão econômica. Ocorre um crescimento do turismo e um desenvolvimento da indústria aeronáutica, que resultam em conjuntura positiva para o setor hoteleiro (ANDRADE et al., 2014; VARGAS, 2016). É neste período que as redes hoteleiras se consolidam. Surgem cadeias relevantes como Best Western (1946), Holiday Inn (1952) e Hyatt (1957). A Marriott e a Kempinsky iniciam suas atividades como redes de restaurantes migram para o ramo de hotelaria neste período. Em 1956, a Sol Hoteles, que viria a se tornar futuramente a Meliá Hotels \& Resorts, inaugura seu primeiro hotel na Espanha.

Os princípios do International Style, baseados na ideia de uma arquitetura universal e reprodutível servem as necessidades de reconstrução e expansão advindas do pós-guerra. A padronização está mais uma vez em pauta. De acordo com Penner:

Durante o pós-guerra nos anos 1950, a padronização de produtos e serviços começa a emergir e as marcas e redes hoteleiras tornam-se a tendência prevalecente nos Estados Unidos e Europa. Esta tendência foi simbolizada pela famosa frase do fundador da rede Holiday Inn, Kemmons Wilson, quando ele cunha o slogan: "A melhor surpresa é não ter surpresas" (PENNER et. al., 2013, p.53, tradução nossa).

Se a partir da década de 1950 as redes ampliam suas expansões geográficas, nos anos 1970, passam pelo processo de internacionalização. Por meio da padronização as redes hoteleiras encontram um meio para disseminar suas linguagens de maneira a serem reconhecíveis pelos seus potenciais usuários.

Porém nota-se que já na década de 1960 começam a emergir vozes que se antepõe ao Internacional Style e à intensa padronização. Evoca-se uma arquitetura menos pasteurizada e as redes hoteleiras se veem nas décadas de 1980 e 1990 diante do desafio de oferecer possibilidades de experiências personalizadas em 
Valente, C. A.; Perrone R. A. C.

cada uma de suas unidades - sem perder suas identidades, atender às demandas que surgem com a elevação de uma nova fase da modernidade.

\title{
Novos paradigmas para a indústria hoteleira
}

Já na década de 1960, o Internacional Style começa a ser contestado. O intenso uso de seu repertório resulta por vezes em uma arquitetura inexpressiva. Venturi aponta uma suposta impessoalidade destas edificações, sinalizando uma perda de comunicação em relação as edificações ecléticas do século XIX:

\begin{abstract}
A arquitetura purista era em parte uma reação contra ecletismo o século XIX. Igrejas góticas, bancos renascentistas e prefeituras jacobinas eram francamente cênicos [...]. Vestidas em estilos históricos, as edificações evocam associações explicitas e alusões ao passado para literalmente vestir o caráter eclesiástico, nacional ou simbolismo programático [...] a sobreposição de estilos pode ter diluído a arquitetura, mas evidenciou seu significado (VENTURI et al., 2001, p.7, tradução nossa).
\end{abstract}

$\mathrm{Na}$ contramão dessa hotelaria massificada, o arquiteto John Portman gera uma quebra de paradigma na hotelaria de luxo ao utilizar o conceito de átrio no Hyatt Regency Atlanta ${ }^{3}$. Tal elemento que há muito não era utilizado, fora introduzido na hotelaria de maneira pioneira no hotel Brown Palace em Denver ${ }^{4}$. O gesto de Portman, ao reintroduzir o átrio, impacta não só a arquitetura de empreendimentos posteriores da rede Hyatt, mas também, em outros hotéis do segmento de luxo (PENNER, 2013). O hotel Macksoud Plaza 5 , inaugurado em São Paulo em 1979, pode se considerado exemplo do emprego desta tipologia (MELACHOS, 2014).

A arquitetura busca novas e variadas expressões, ao passo que uma nova modernidade começa a se desenhar, na qual o consumo não está somente atrelado à função, mas também à "democratização do lazer cultural, no consumo experimental" (LIPOVSTISKY; CHARLES, p.88). Lash e Urry (2002) reforçam esta ideia ao sinalizarem que o que a humanidade produz são mais que objetos, mas atributos estéticos capazes de produzir representações e símbolos. Em uma nova visão da modernidade tem-se além do individualismo, uma intensificação da busca de sensações e prazer como sinaliza Vilém Flusser:

O novo homem não é mais uma pessoa de ações concretas, mas sim um performer [...]: Homo ludens, e não Homo faber. Para ele, a vida deixou de ser um drama e passou a ser um espetáculo. Não se trata mais de ações, e sim de sensações. O novo homem não quer ter ou fazer, ele quer vivenciar. Ele deseja experimentar, conhecer e, sobretudo, desfrutar (FLUSSER, 2013, p. 58).

Alinhado ao paradigma da experiência, do desfrutar, ao final da década de 1970 surgem os hotéis Boutique. Segundo Penner (2013), o pioneiro desta nova categoria é o Blakes Hotel, concebido por Anouska Hempel e inaugurado em 1979.

O Blakes Hotel se apropria de uma edificação existente em South Kensington, Londres. Possui poucos apartamentos, porém, esses apresentam grande variedade de arranjos espaciais e de elementos em sua decoração. O mobiliário traz referências de diversas épocas. Contudo, tais peças se integram e são alçadas a uma condição contemporânea, diante do emprego de cores como preto, branco e cinza - tais cores aplicadas aos acabamentos não pertencem à paleta original da edificação e nem tão pouco aos elementos que compõe a arquitetura de interiores ${ }^{6}$. $O$ arranjo espacial, os acabamentos e as sobreposições de materiais, trazem outras representações, ou seja, são acoplados às funções originais, outros hábitos, outros arranjos estéticos e ressignificações. Baudrillard afirma que um objeto deslocado do seu contexto e da sua época de manufatura, ganha outro estado de presença, gerando também outras experiências. Assim o objeto "é vivido de outra maneira".

O objeto antigo é sempre, no sentido exato do termo, um "retrato de família". Existe sob a forma concreta de um objeto, a imemorialização de um precedente - processo que equivale, na ordem imaginária, a uma elisão do tempo (BAUDRILLARD, 2009, pp.83-84).

O bairro onde está localizado o Blakes Hotel apresenta além da ocupação residencial, um uso comercial. Trata-se de uma região servida por equipamentos culturais relevantes, tais como o Natural History Museum, o Science Museum, o Victoria and Albert Museum, o Royal Albert Hall, o Imperial College London, o Royal Geographical Society, o Royal College of Art e o Royal College of Music. As características de arquitetura, assim como as de localização do Blakes Hotel traduzem o conceito de hotel Boutique assinalados por Penner (2013): hotéis voltados para o seguimento de luxo, com poucos apartamentos, frequentemente locados em edificações existentes em áreas relevantes de centros urbanos e possuem o enfoque de oferecer aos seus usuários experiências diferenciadas.

A partir da década de 1980, os hotéis boutique se disseminam pelos Estados Unidos. Penner (2013) aponta que uma das primeiras inciativas vem de Bill Kimpton que, em 1981, inicia as operações do Bedford Hotel 
em San Francisco. Em 1984, é inaugurado em Nova lorque, o Morgans Hotel (Fig.1), projeto de Andrée Putman $^{7}$, sob a encomenda de lan Schrager ${ }^{8}$, que se apropria do edifício de um antigo hotel decadente. A remodelação desse edifício visa atingir um público, envolvido pelo universo midiático, dominado pela presença de artistas, modelos, publicitários, empresários e outros profissionais liberais. Assim, a designer cria representações imagéticas ligadas às artes plásticas e a ícones que aludem à própria cidade onde se localiza o hotel. Cidade esta, reconhecida por sua movimentação artística e pela intensidade de suas atividades comerciais (BANGERT; RIETWOLT, 1993). O sucesso desse hotel leva lan Schrager a abrir novos empreendimentos, desta vez assinados pelo designer Philippe Starck, dando origem a uma pequena cadeia de hotéis.

Figura 1: Saguão de entrada do Morgans Hotel em 2015. Nesta data o ambiente apresenta pequenas alterações realizadas pelo escritório de Andrée Putman. As modificações se resumem em pequenas mudanças das tonalidades, preservando as referências Art Decó do projeto original da própria designer inaugurado em 1984.

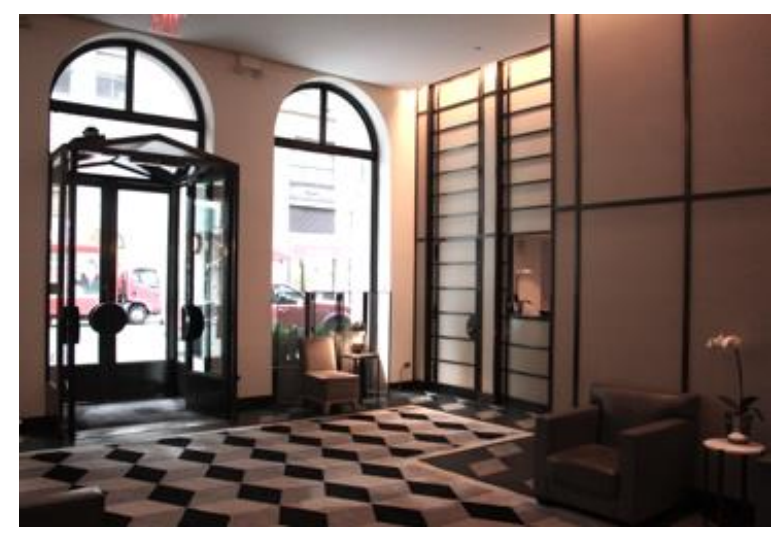

Fonte: Acervo dos autores.

À medida que a conceito de hotel boutique se dissemina, surgem empreendimentos que distorcem suas características originais, como exemplo, tem-se o Hudson Hotel, inaugurado em 2000, pertencente ao Morgans Group, que conta com mais de 1000 apartamentos. Ao reformar a edificação, que originalmente pertence à Associação Cristã de Moços, a rede mantém a maioria dos pequenos alojamentos em suas dimensões originais e trabalha com tarifas econômicas (Fig. 2). A remodelação, assinada por Starck, traz aspectos presentes em outros hotéis do segmento, tais como, a apropriação do edifício existente e a ressignificação de elementos de diferentes épocas. Porém, os apartamentos apresentam traços encontrados em hotéis econômicos, como: o uso de armários sem portas e quantidades reduzidas de móveis, devido a pouca disponibilidade de espaço.

Figura 2: Apartamento do Hudson Hotel com dimensões bastante reduzidas em relação aos padrões estadunidenses.

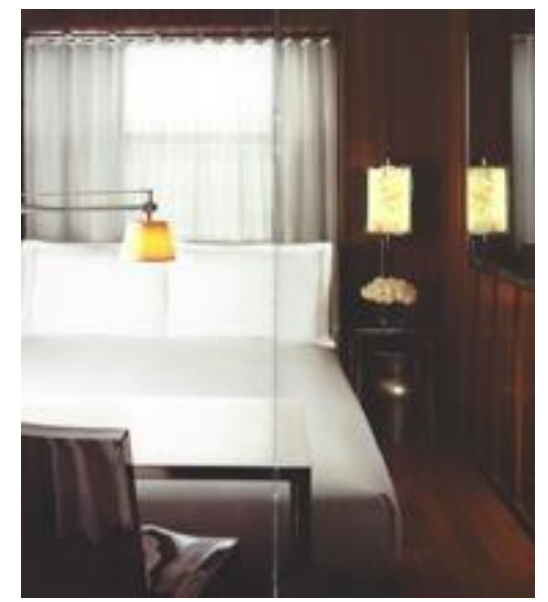

Fonte: Brochura publicitária do Morgans Group de 2006, do acervo dos autores.

Sobre esses aspectos, Penner (2013) afirma que qualificar tais hotéis como boutique torna-se algo inadequado. $\mathrm{O}$ autor aponta que a mídia especializada em hotelaria sente necessidade de reclassificá-los, uma vez que tal insígnia se destina a hotéis de pequena escala e com serviços personalizados. Nessa direção, inicia-se o processo de enquadrá-los como hotéis Design.

Dentro deste quadro pode-se dizer que os hotéis Boutique trazem uma nova categoria de hotéis de luxo, cujo conceito está em possibilitar experiências a seus hóspedes. Porém sua derivação, os hotéis Design, 
conferem uma democratização deste conceito estendendo-o também para as categorias mais econômicas. $\mathrm{Na}$ década de 1990 as grandes redes hoteleiras se apropriam do conceito dos hotéis Boutique e Design, gerando os chamados Lifestyle Hotels, categoria de hotéis de luxo que oferecem experiências por meio do design, porém com quantidades de apartamentos menos reduzidas que o Boutique e arquitetura contemporânea.

Assim, ao se observar o histórico das redes hoteleiras nota-se que as mesmas guardam uma relação estreita com a padronização. A razão da escolha de um hotel de rede a outro está na possibilidade de obter um produto com certas características determinadas. Nota-se, porém, que a mera repetição de elementos está aquém das expectativas contemporâneas por experiências. Desta forma, abra-se a questão de como uma rede pode manter suas marcas reconhecíveis por seu público por meio de uma linguagem comum a seus hotéis, sem constituir-se de uma simples repetição de elementos.

\section{A linguagem das redes hoteleiras: elementos repetitivos e singulares}

Ao se observar hotéis de rede, verifica-se que muitos obtêm uma linguagem reconhecível por meio do uso de elementos repetitivos. Arquitetura de interiores de saguões de entrada e apartamentos são praticamente idênticos remetendo ainda ao conceito de Kemmons Wilson, fundador da rede Holiday Inn, como já assinalado: "a melhor surpresa é não ter surpresas".

Por outro lado, há uma gama de hotéis de rede, nos quais não se verificam uma arquitetura repetitiva, mas sim uma ambiência comum com seus pares, traduzindo-se em uma linguagem reconhecível para seus hóspedes. Para uma melhor percepção desse fenômeno, recorre-se às ferramentas de interpretação para análise de obras arquitetônicas utilizadas por Clark e Pause (2005). De acordo com estes autores, relacionar os elementos repetitivos e singulares de uma edificação implica "[...] no estabelecimento de relações entre componentes que têm múltiplas e singulares manifestações" (CLARK; PAUSE, 2005. p.22).

Ao extrapolar essa mesma ideia na análise dos elementos utilizados pela rede Hyatt, observa-se que os saguões de entrada do Grand Hyatt São Paulo e do Grand Hyatt New York apresentam semelhanças e peculiaridades (Fig. 3 e 4). Tais saguões possuem uma série de elementos repetitivos como o uso de acabamentos em materiais naturais aparentes, como pedras e madeiras, predileção por cores neutras, como preto, branco, tons de cinza e variações de marrom.

Figura 3: Saguão de entrada do hotel Grand Hyatt São Paulo em 2017.

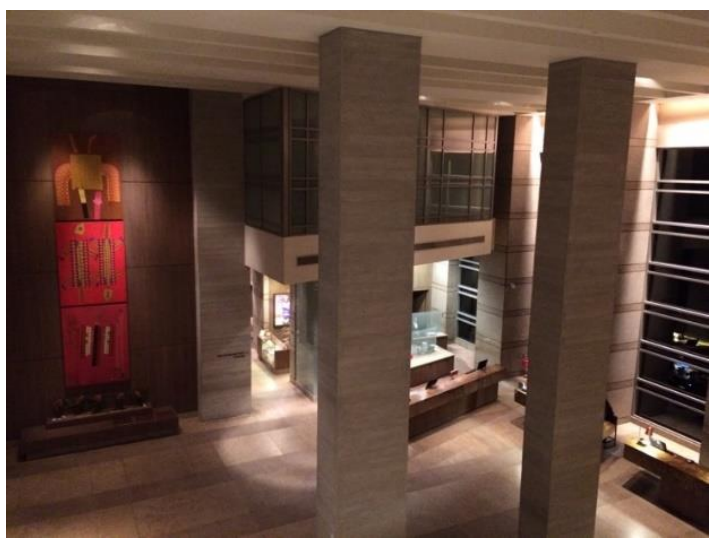

Fonte: Acervo dos autores.

Figura 4: Saguão de entrada do hotel Grand Hyatt New York em 2015.

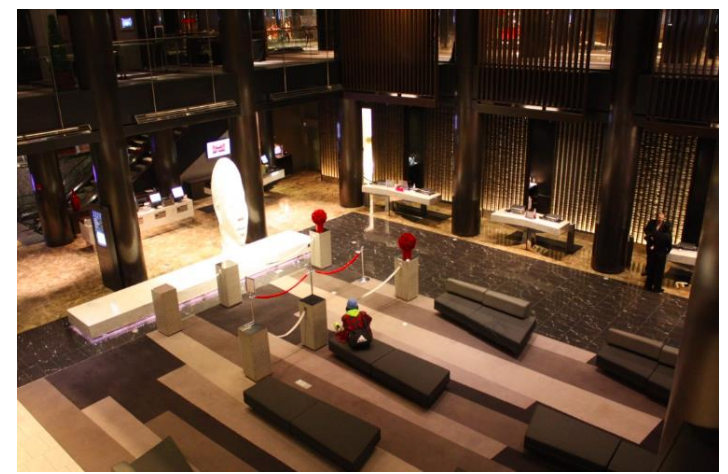

Fonte: Acervo dos autores. 
Porém, o mobiliário destas duas unidades não é idêntico, apesar de apresentarem pontos em comum, tais como, peças de linhas retas. Mesmo verificando uma preocupação com o desenho de cada peça, o resultado final é uma homogeneidade, conferida pelo emprego de uma paleta de cores concisa e sem grandes contrastes.

Os balcões de recepção do Grand Hyatt New York e do Grand Hyatt São Paulo possuem características semelhantes, a partir de diversos aspectos: em ambos os casos o móvel não se configura como um balcão único, mas sim vários balcões ocupados cada um por dois atendentes (Fig. 5). À primeira vista já se percebe que esses balcões são formados por um volume superior horizontal em pedra com formato de paralelepípedo. Tal elemento faz contraponto com a base que o sustenta. $O$ tampo que parece muito pesado pousa delicadamente sobre uma base aparentemente diminuta para suportar tal peso. A base do balcão do Grand Hyatt New York é de aço inox polido - o que permite que esse elemento se torne visualmente mais leve do que é na verdade. Como esse material é refletivo, a base pode ser camuflada ao espelhar os demais elementos da recepção, dependendo do ângulo de visão do observador. Comparada ao exemplar de Nova lorque, a base do balcão do Grand Hyatt São Paulo, representa um maior peso, pois se constitui de um volume de madeira. Contudo, suas proporções em relação ao tampo fazem com que o elemento superior se destaque. Em ambos os casos, tem-se a impressão que, de alguma forma, tais tampos estão praticamente flutuando no ambiente.

Figura 5: Modelos de balcões dos hotéis Grand Hyatt São Paulo e Grand Hyatt New York, respectivamente. Imagens realizadas no ano de 2015.

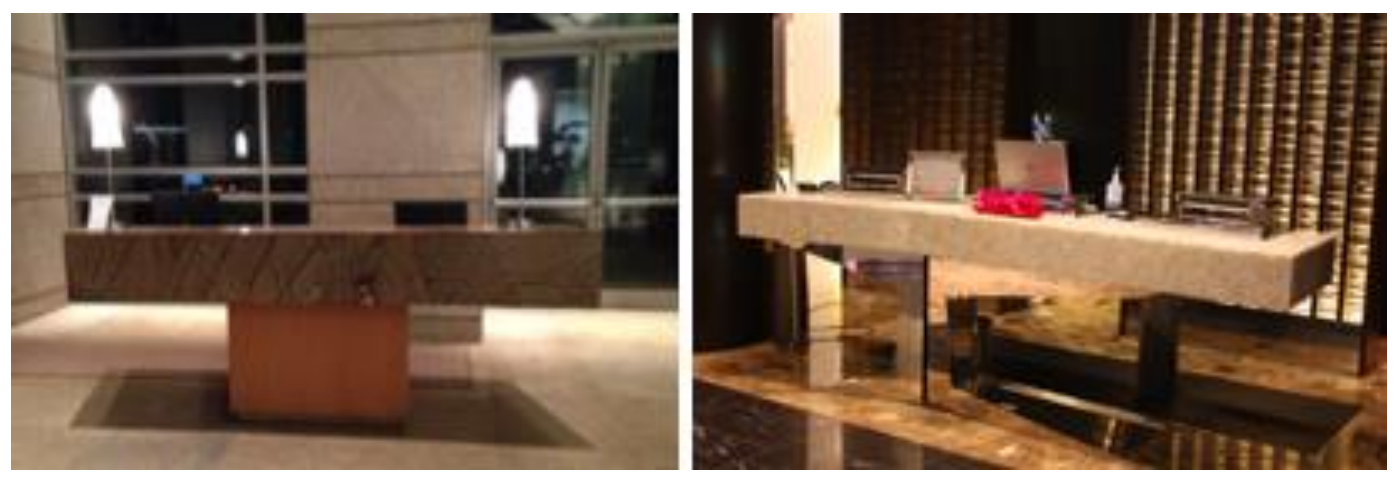

Fonte: Acervo dos autores.

Esses balcões se diferem bastante dos balcões tradicionais de hotel. Não fosse a presença dos atendentes e dos notebooks em sua superfície, podem ser lidos como aparadores ou outro tipo de mobiliário. Os balcões tradicionais de recepção apresentam, em geral, dois níveis: o lado mais alto volta-se para a área pública do lobby e é destinada a atuação do cliente. Na superfície mais baixa, o atendente realiza suas tarefas. Trata-se de uma área operacional, onde as ações realizadas, assim como equipamentos, ficam parcialmente fora da visão do cliente (Fig. 6). Tradicionalmente, o balcão de recepção separa fisicamente a área operacional da área pública, sendo que para o atendente acessar o lobby, geralmente, necessita passar por um corredor lateral intermediário.

Figura 6: Corte de balcão tradicional: diferença de nível de tampos define as áreas de clientes e de atendentes. O corpo do balcão serve de isolamento entre a área de clientes e a área operacional.

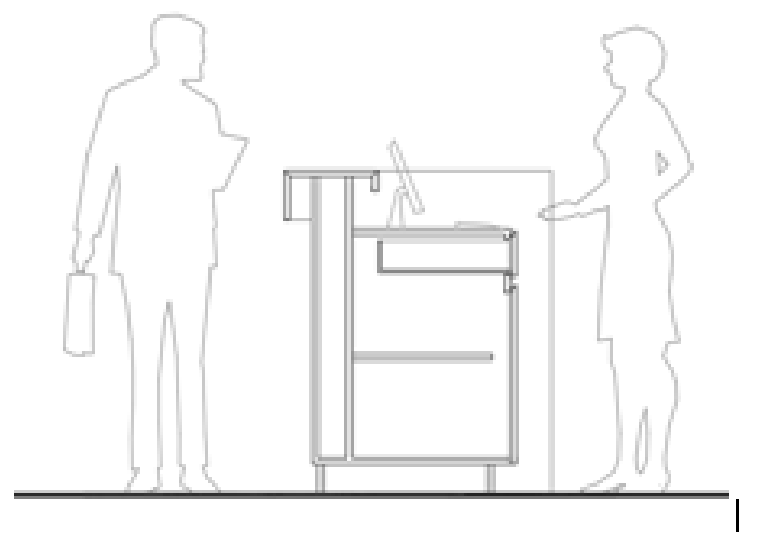

Fonte: Acervo dos autores. 
Valente, C. A.; Perrone R. A. C.

Dentro dessa perspectiva, verifica-se que os balcões do Grand Hyatt New York e do Grand Hyatt São Paulo apresentam não só um desenho diferenciado em relação ao balcão tradicional, mas também peculiaridades ligadas ao serviço prestado. A base reduzida desses balcões permite a visão, praticamente, completa do corpo do atendente. A superfície onde atuam o atendente e o cliente é única, não apresentando desníveis. É possível circular livremente em torno dos balcões. Ao invés de compor-se por um elemento único a recepção fragmenta-se em vários módulos de atendimento.

Ambos saguões de entrada apresentam organização espacial semelhantes. São espaços ao redor dos quais se organizam as demais áreas destes hotéis. Neste ponto se aproximam do conceito do átrio proposto por Portman para o Hyatt Regency Atlanta.

Apesar da presença dos elementos repetitivos apresentados, observa-se também a presença de elementos singulares de cada um destes saguões de entrada. O Grand Hyatt New York apresenta por exemplo duas esculturas de grande escala do artista plástico Jaume Pleusma ${ }^{9}$, elementos de características bastante peculiares e que resultam em um aspecto particular a este saguão.

Os apartamentos do Grand Hyatt São Paulo e do Grand Hyatt New York, possuem também elementos repetitivos e singulares. Os elementos essenciais da hospedagem como a composição de cama possuem o mesmo padrão. Utiliza-se o mesmo tipo de colchão, cama e enxoval e segue-se a mesma montagem. Outros elementos repetitivos são o uso de revestimentos em cores neutras como preto e branco, assim como variações de marrons e cinza. Os revestimentos em madeira estão presentes em abundância nas duas unidades.

Nota-se também a existência de elementos singulares. Há móveis nas duas unidades que seguem a mesma linha de desenho, porém não há um padrão rígido. Poltronas e mesas de trabalho apresentam diferentes leituras. A cabeceira do Grand Hyatt New York, apresenta um elemento que não se encontra em outros hotéis da marca. Trata-se de um trabalho artístico, desenvolvido especialmente para a unidade e com tom avermelhado um pouco diferente da paleta de cores utilizado nos demais apartamentos da marca (Fig. 7 e 8).

Figura 7: Interiores dos apartamentos do Grand Hyatt São Paulo em 2016.

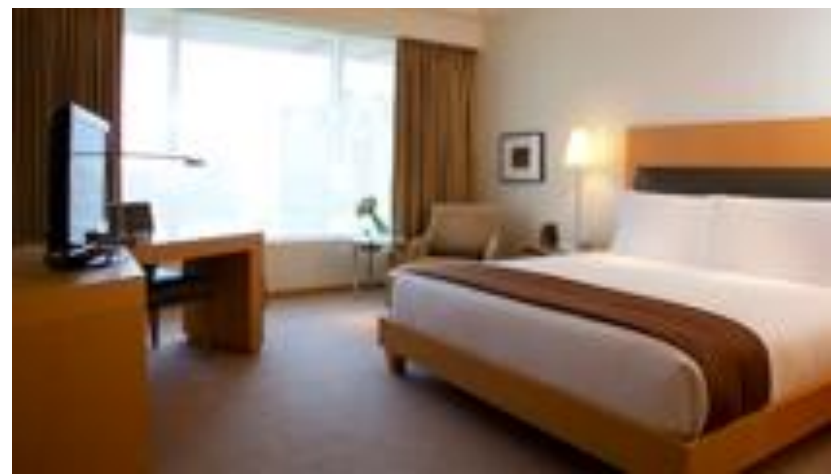

Fonte: www.hyatthotels.com

Figura 8: Interiores dos apartamentos do Grand Hyatt New York em 2016.

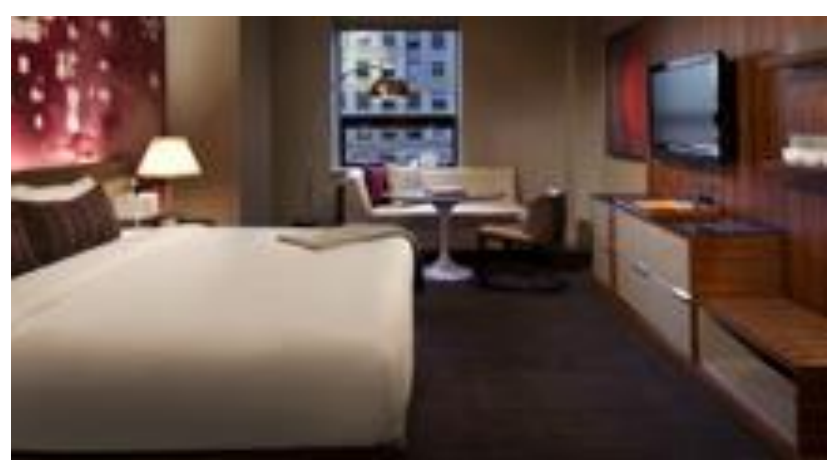

Fonte: www.hyatthotels.com

Ao observar-se outros hotéis da marca Grand Hyatt, verifica-se a existência dos mesmos elementos repetitivos apontados nas unidades de São Paulo e Nova lorque, ainda que estes apartamentos também contenham elementos singulares ${ }^{10}$. 
Os elementos repetitivos se fazem presentes no imaginário e na memória do público por meio de seus aspectos sensoriais. Os autores destacados, nessa pesquisa, são praticamente unanimes em assinalar os aspectos ligados à visão como um dos primeiros a serem percebidos e reconhecidos. Outras sensações, como as relativas ao tato, podem ser pressentidas pela visão. Ao se olhar o enxoval, pode-se presumir sobre a maciez do mesmo. Ressalta-se que a visão é um dos principais sentidos trabalhados nas mídias, especialmente publicações, cinema e televisão. Portanto, tudo o que diz respeito à visão, como paleta de cores, formas, características de iluminação e símbolos, costumam ser a primeira comunicação fixada entre o usuário e o hotel, geralmente, já no momento de escolha. Nesse sentido, pode-se dizer que a visão estabelece uma conexão com o imaginário do público.

Porém, outros aspectos sensoriais também se fazem importantes e têm ligação com a memória, são eles: 0 olfato, o tato e o paladar. Os estudos verificam que o enxoval é um dos possíveis elementos repetitivos de maior poder conexão com o público. A quantidade de fios e seus materiais de composição determinam, além de aspectos visuais do tecido, como brilho, sensações táteis. O olfato também se faz presente, constantemente, por meio de fragrâncias específicas para cada marca, que são aspergidas pelo sistema de ar condicionado ou se encontram nos amenities ${ }^{11}$. Por essa razão, a maioria das redes desenvolve fragrâncias distintas para suas marcas. O paladar pode ser percebido em amenidades, tais como os chocolates usados nas aberturas de cama realizadas em hotéis de categorias superiores. Percebe-se, então, que se os aspectos sensoriais se fazem presentes nos elementos repetitivos, há elementos que condensam diferentes aspectos, como por exemplo, o enxoval que envolve a visão, o tato e até o olfato; ou ainda, os chocolates de abertura de cama que abrangem a visão e o paladar. Criam-se, assim, fluxos de conexões entre a memória e o imaginário do usuário.

\section{CONSIDERAÇÕES FINAIS}

Elementos repetitivos e singulares estão presentes nos empreendimentos de hoteleiros de pioneiros como Cesar Ritz e Conrad Hilton. Esses hotéis já apresentavam uma série de padrões, mas não eram idênticos.

Contudo, com a expansão e disseminação, em larga escala, das redes hoteleiras, verifica-se a partir da década de 1950, uma preponderância na utilização dos elementos repetitivos, o que acabou por gerar, por vezes, edificações idênticas.

Se por um lado, durante um período, essa preponderância foi uma ferramenta eficiente na disseminação das linguagens dessas redes, por outro, com a consumação de uma nova modernidade, foi necessário acoplar singularidades a esses projetos de forma a atender às demandas dos hóspedes por experiências personalizadas, levando em consideração características geográficas e culturais de cada destino. Ou seja, pode-se depreender que os hotéis de rede, além de elementos repetitivos, apresentam particularidades de design em cada uma das suas unidades. Nota-se que essas especificidades decorrem das características do local, onde a construção está inserida - formato e dimensões de terreno, contexto de entorno e questões culturais, impactando na sua concepção e configuração final. Nomeiam-se esses elementos como singulares (VALENTE, 2017).

Os elementos singulares têm a capacidade de trabalhar com a memória e o imaginário, mas não da marca especificamente e sim daquela unidade da qual fazem parte, como assinalam alguns exemplos apresentados neste artigo.

\section{REFERÊNCIAS}

ANDRADE, Nelson; BRITO, Paulo Lucio de; JORGE, Wilson Edson. Hotel: planejamento e projeto. São Paulo: Editora Senac, 2014.

BAUDRILLARD, Jean. O sistema dos objetos. São Paulo: Editora Perspectiva, 2009.

CLARK, Roger H. e PAUSE, Michael. Precedents in Architecture - Analytic Diagrams, Formative Ideas, and Partis (Third Edition). New Jersey: John Wiley \& Sons, 2005.

HALL, Edward T. A dimensão oculta. São Paulo: Martins Fontes, 2005.

HAUFFE, T. Design: a concise history. Nova York: L. King, 1995.

LASH, Scott e URRY, John. Economies of signs and space. London: SAGE Publications, 2002.

LIPOVETSKY, Gilles; CHARLES, Sebastien; VILELA, Mario. Os tempos hipermodernos. São Paulo: Barcarolla, 2005.

MELACHOS, Felipe Corres. Transformações na arquitetura hoteleira em São Paulo: hotéis centrais de padrão superior: 1954 a 2004. 2014. Dissertação (Mestrado em Arquitetura e Urbanismo) - Universidade Presbiteriana Mackenzie, 2014. 
MILENKOVSKA, Violeta. Contemporary tendencies in the tourism operation. UTMS journal of economics, Skopdge, v.2, p.37-50, jun.2011.

PENNER, Richard H.; ADAMS, Laurence; ROBSON, Stephani K. A. Hotel: Planning and Development. New York: W. W. Norton \& Company, 2013.

VALENTE, Claudio Alexandre. Redes hoteleiras: linguagem e disseminação nas suas expansões. 2017. Dissertação (Mestrado em Arquitetura e Urbanismo) - Universidade Presbiteriana Mackenzie, 2017.

VENTURI, Robert; BROWN, Denise Scott; IZENOUR, Steven. Learning from Las Vegas. Massachusetts: Massachusetts Institute of Technology, 2001.

\section{Sites visitados:}

http://www.blakeshotels.com/gallery

http://brown-palace-denver.hotel-rn.com/?|bl=ggl-ex

http://maksoud-plaza-saopaulo.hotel-rn.com/index.htm?lbl=gglrmk

https://www.morganshotelgroup.com/hudson/hudson-new-york

https://www.morganshotelgroup.com/originals/originals-morgans-new-york

https://mumbai.grand.hyatt.com/en/hotel/home.html

https://newyork.grand.hyatt.com/en/hotel/home.html

https://www.portmanusa.com/en/projects/hospitality/hyatt-regency-atlanta?lite_escape=

https://saopaulo.grand.hyatt.com/pt/hotel/home.html?\&mckv=sSCa7lelZ_pdv_c_pcrid_120290427179_pmt_e_pkw_gran d\%20hyatt\%20s\%C3\%A30\%20paulo\&src=agn_pfx_ppc_latam_Brand_Sao+Paulo_PT̄_google_Brand_Sao+Paulo_PT_ $\mathrm{GH}+\mathrm{SaO}+$ Paulo_Exact_e_grand\%20hyatt\%20s\%C3\%A30\%20̄paulo_Brand

https://sanfrancisco.grand.hyatt.com/en/hotel/home.html

https://singapore.grand.hyatt.com/en/hotel/home.html

https://tokyo.grand.hyatt.com/en/hotel/home.html

https://washingtondc.grand.hyatt.com/en/hotel/home.html

\section{NOTAS}

${ }^{1}$ Este trabalho pode ser acessado na integra por meio do endereço eletrônico http://tede.mackenzie.br/jspui/handle/tede/3285.

2 Ao longo do texto, surgem os termos cadeia hoteleira, marca e bandeira - todos imbricados diretamente com o conceito de rede hoteleira. Nesse sentido, cadeia hoteleira deve ser entendida como sinônimo de rede hoteleira; bandeira é o termo empregado como sinônimo de marca. Observe-se que uma rede hoteleira ou uma cadeia hoteleira pode ser constituída por diversas marcas ou bandeiras diferentes entre si e essas administradas sob as consignas da cadeia hoteleira. A rede hoteleira Hyatt, por exemplo, possui as marcas Hyatt Park, Grand Hyatt, Hyatt Regency, Hyatt Park e Andaz, entre outras. Vale ainda apontar que o termo unidade, corrente no meio hoteleiro, é usado como sinônimo de hotel.

${ }^{3}$ Imagens referenciais do átrio do saguão de entrada do hotel Hyatt Regency Atlanta estão disponíveis no sítio eletrônico do escritório do Arquiteto John Portman: _https://www.portmanusa.com/en/projects/hospitality/hyatt-regency-atlanta?lite_escape=1

${ }^{4}$ Imagens referenciais do átrio do saguão de entrada do hotel Brown Palace podem ser obtidas no seguinte sítio eletrônico: http://brown-palace-denver.hotel-rn.com/?lbl=ggl-ex

${ }^{5}$ Imagens referenciais do átrio do saguão de entrada do hotel Maksoud Plaza podem ser obtidas no seguinte sítio eletrônico:
http://maksoud-plaza-saopaulo.hotel-rn.com/index.htm?lbl=gglrmk

${ }^{6}$ Imagens referenciais da fachada e dos interiores do Blakes Hotel podem ser obtidas no sítio eletrônico http://www.blakeshotels.com/gallery

${ }^{7}$ Andrée Putman é uma designer de interiores francesa, reconhecida pelo empenho na democratização do design.

${ }^{8}$ lan Schrager é um empresário que, na década de 1970, ganha notoriedade por estar à frente de famosas casas noturnas, como a Studio 54, em Nova lorque. A partir da experiência do Morgans Hotel, o empresário lidera novas empreitadas na área de hotelaria, especialmente nas décadas de 1980 e 1990. Recentemente, Schrager faz incursões no ramo de empreendimentos imobiliários.

${ }^{9}$ Jaume Plensa é um artista plástico espanhol, conhecido por suas obras de grande escala para espaços públicos. Entre suas obras mais populares, está a Fonte Crown, no Millenum Park, em Chicago. 
${ }^{10}$ Imagens de apartamentos de hotéis da marca Grand Hyatt podem ser obtidas nos seguintes sítios eletrônicos:

Grand Hyatt Mumbai: https://mumbai.grand.hyatt.com/en/hotel/home.html

Grand Hyatt San Francisco: https://sanfrancisco.grand.hyatt.com/en/hotel/home.html

Grand Hyatt Singapore: https://singapore.grand.hyatt.com/en/hotel/home.html

Grand Hyatt Tokio: https://tokyo.grand.hyatt.com/en/hotel/home.html

Grand Hyatt Washington: https://washingtondc.grand.hyatt.com/en/hotel/home.html

Por meio destas imagens é possível fazer comparações com os hotéis Grand Hyatt São Paulo e Grand Hyatt New York.

11 Amenities é um termo corrente na área de hotelaria. Trata-se de itens de higiene pessoal e conveniência que são oferecidos gratuitamente aos hóspedes de hotéis.

NOTA DO EDITOR (*) O conteúdo do artigo e as imagens nele publicadas são de responsabilidade do(s) autor(es). 